\title{
A Better Understanding of Relationship between Job Satisfaction and Affective Organizational Commitment
}

\author{
Rashed Alneyadi, Mohammed Nusari, Ali Ameen, Amiya Bhaumik
}

\begin{abstract}
The public sector in $U A E$ is the focus of this paper. Applying the concept of job satisfaction to examine its effect on employees' affective organizational commitment. The data was collected from 452 officers from 7 sectors in the ministry of interior in UAE and analysed using structural equation modelling via SmartPLS 3.0. The result showed that job satisfaction has a positive impact on affective organizational commitment. The proposed model explained $11.4 \%$ of the variance in employees' affective organizational commitment.
\end{abstract}

Keywords: Job satisfaction; affective organizational commitment (AOC).

\section{INTRODUCTION}

ternational competition and globalization have rendered the recruitment, maintenance, and organization of resources, decisive factors for success in the public sector domain. In the services sector, it is acknowledged that the management of human resources, in particular, is a crucial factor. This is attributed to the fact that the services offered, and the supplier of these services, are, to a large extent, interconnected. In this regard, enhancing an employee's job satisfaction, dedication to the organization and motivation, will serve to promote his/her extra-role behaviour, by way of organizational citizenship behaviour. This, in turn, will contribute towards an improved standing of the public sector organization concerned, in terms of competitiveness. The close relationship between job satisfaction, and performance, is particularly evident in the service industry.

During previous studies, investigators identified three attributes of organizational commitment. Namely, these are affective organizational commitment (AOC), normative organizational commitment (NOC), and continuance organizational commitment (COC). While it was established that affective commitment constantly leads to an enhancement in work performance, a reduction in the occurrence of absenteeism, and a cutback in staff turnover, studies on the influence of normative and continuance commitments, with regards to on-the-job behaviour, turned up contradictory

Revised Manuscript Received on September 25, 2019

Rashed ALNEYADI, Faculty of Business and Accountancy, Lincoln University College, Selangor, Malaysia

Mohammed NUSARI, Faculty of Business and Accountancy, Lincoln University College, Selangor, Malaysia

Ali Ameen, Faculty of Business and Accountancy, Lincoln University College, Selangor, Malaysia

Amiya Bhaumik, Faculty of Business and Accountancy, Lincoln University College, Selangor, Malaysia outcomes. Several investigators are of the opinion that continuance commitment is irrelevant, or in a worst case scenario detrimental, when it comes to efforts aimed at realizing a positive job behaviour. It was also suggested that the limited studies on normative and continuance commitments, are due to the complexities involved in the conceptualization, and measurement, of the variables, as well as their antecedents.

This current study focuses on the association between job satisfaction and affective organizational commitment with respect to the UAE Police department.

\section{LITERATURE REVIEW}

\section{A. Affective Organizational Commitment (AOC)}

Organizational commitment considers the psychological connection between an employee and the organization. A wide range of organizational commitment concepts and methods, can be gleaned from literature relevant to this subject matter. Organizational commitment is described as "the relative strength of an individual's identification with involvement in a particular organization". It can also be deemed a course of action for the gradual integration of the individual's aspirations, and the aspirations of the organization. The research separated affective organizational commitment into three components: normative commitment, affective commitment and continuance commitment.

\section{B. Job Satisfaction (JS)}

JS has to do with the attitudes or opinions of employees regarding their work specifically or their work setting as a whole, and their general sentiment as regards to their job requirements. The origins of the job satisfaction concept can be traced to an investigation conducted in the 1920s, which came to be known as the Hawthorne studies. The outcomes from this endeavour revealed that the emotions of a worker, has a significant effect on his/her behaviour at work. The job satisfaction and productivity levels of an employee are determined principally by his/her social and psychological circumstances.

Job satisfaction refers to an individual's response to his/her working situation. This response arises from a comparison between the real situation, and the situation that 
is anticipated, craved and required. Personal in nature, this response is indicative of the degree of contentment an employee experiences with regards to his/her job. Consequently, the following hypothesis is proposed:

H1. JS has a positive impact on affective organizational commitment.

Figure 1 presents the study model that contains one independent variable (JS) and one dependent variable (affective organizational commitment).

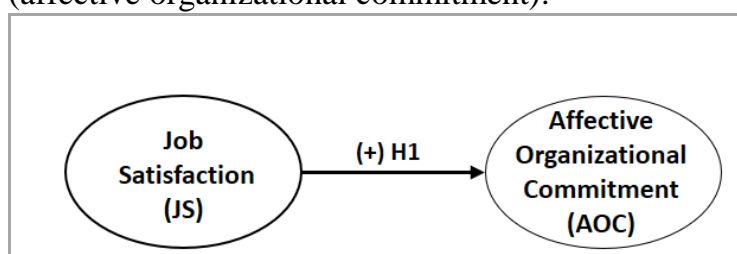

(+) Positive Relationship

Fig. 1 The proposed model

\section{RESEARCH DESIGN AND METHODOLOGY}

\section{A. Instrument Development}

Equipped with information available in relevant literature, we applied a multi-item Likert scale for a 9-item questionnaire. As recommended in previous investigations, the constructs were gauged with the use of a 5-point Likert scale [1-3], with 5 signifying 'Strongly Agree' and 1 signifying 'Strongly Disagree'. Taking into consideration the fully Arab-speaking composition of respondents, the items in the questionnaire were accurately translated from English to Arabic. Back translation, a procedure frequently applied in cross-cultural surveys, was employed for this purpose. We referred to previous studies for the gauging of the variables (Appendix A). The guidelines were adhered to for approximating the number of items for each construct. were considered for our survey. This sample size is similar to that used by Krejcie \& Morgan (1970) [4] for their study in this area. Our realized response rate of $60.42 \%$ can be deemed excellent, when compared to those of previous investigations, documented in relevant literature. Of the 28 removed questionnaires, 21 were found to have omitted answers to more than $15 \%$ of the questions, three were outliers, and 4 came with a straight lining.

\section{Data Analysis and Results}

The SmartPLS 3.0 software was used to examine our model through PLS variance-based SEM. A two-stage analytical procedure was utilized for (a) evaluating the measurement model (validity and reliability), and (b) evaluating the structural model (hypothesized relationships analysis).

\section{A.Descriptive analysis}

Job satisfaction score the highest with mean 3.356 out of 5.0, with a standard deviation of 1.148. Affective Organizational Commitment score the lowest with mean 2.995 out of 5.0 , with a standard deviation of 0.949 , as Table 1.

\section{B.Measurement Model Assessment}

The measurement model was assessed for construct reliability and validity. The values of every single Cronbach's alpha surpassed the targeted value of 0.7 [5]. Additionally, the test for construct reliability revealed that every composite reliability (CR) value, also went beyond 0.7 $[6,7]$. Factor loadings were used to evaluate indicator reliability. Except for AOC6, the values recorded exceeded the sought after value of 0.7 . AOC6 was subsequently discarded from the scale, due to depleted loading values. Convergent validity was evaluated by way of average variance extracted (AVE). The values attained topped the objective value of 0.50 . These evaluation results are exhibited in Table 1.

\section{B. Data Collection}

Between April, 2018 and August, 2018, 600 self-administered questionnaires were handed out to government workers. Of these, 480 were returned, and 452

Table 1: Measurement assessment results

\begin{tabular}{|c|c|c|c|c|c|c|c|}
\hline Constructs & Item & $\begin{array}{c}\text { Loading } \\
(>0.5)\end{array}$ & M & SD & $\begin{array}{c}\alpha \\
(>0.7)\end{array}$ & $\begin{array}{c}\mathrm{CR} \\
(>0.7)\end{array}$ & $\begin{array}{c}\text { AVE } \\
(>0.5)\end{array}$ \\
\hline Job & JS1 & 0.933 & \multirow{3}{*}{3.356} & \multirow{3}{*}{1.148} & \multirow{3}{*}{0.921} & \multirow{3}{*}{0.950} & \multirow{3}{*}{0.864} \\
\hline \multirow{2}{*}{$\begin{array}{c}\text { Satisfaction } \\
\text { (JS) }\end{array}$} & $\mathrm{JS} 2$ & 0.919 & & & & & \\
\hline & JS3 & 0.936 & & & & & \\
\hline \multirow{6}{*}{$\begin{array}{c}\text { Affective } \\
\text { Organizational } \\
\text { Commitment } \\
\text { (AOC) }\end{array}$} & AOC1 & 0.930 & \multirow{6}{*}{2.995} & \multirow{6}{*}{0.949} & \multirow{6}{*}{0.925} & \multirow{6}{*}{0.942} & \multirow{6}{*}{0.767} \\
\hline & AOC2 & 0.929 & & & & & \\
\hline & AOC3 & 0.919 & & & & & \\
\hline & $\mathrm{AOC} 4$ & 0.788 & & & & & \\
\hline & AOC5 & 0.800 & & & & & \\
\hline & AOC6 & Deleted & & & & & \\
\hline
\end{tabular}

Note: $\mathrm{M}=$ Mean; $\mathrm{SD}=$ Standard Deviation, $\alpha=$ Cronbach's alpha; $\mathrm{CR}=$ Composite Reliability, AVE = Average Variance Extracted.

Key: JS: Job Satisfaction, AOC: Affective Organizational Commitment

The discriminant validity of the measurement model was assessed through cross-loadings and the Fornell-Larcker criterion. Cross-loadings are typically the initial step for tests on the discriminant validity of indicators. The requirements the indicators' outer loadings on a construct, surpassed its cross-loadings with other constructs. The evaluation results for discriminant validity through cross-loadings are displayed in Table 2.

for discriminant validity in our model were considered met, as

Table 2: Results of discriminant validity by the cross loading 


\begin{tabular}{c|cc}
\hline & $J S$ & $A O C$ \\
\hline JS1 & $\mathbf{0 . 9 3 3}$ & 0.304 \\
JS2 & $\mathbf{0 . 9 1 9}$ & 0.281 \\
JS3 & $\mathbf{0 . 9 3 6}$ & 0.351 \\
AOC1 & 0.312 & $\mathbf{0 . 9 3 0}$ \\
AOC2 & 0.335 & $\mathbf{0 . 9 2 9}$ \\
AOC3 & 0.359 & $\mathbf{0 . 9 1 9}$ \\
AOC4 & 0.224 & $\mathbf{0 . 7 8 8}$ \\
AOC5 & 0.201 & $\mathbf{0 . 8 0 0}$ \\
\hline
\end{tabular}

Key: JS: Job Satisfaction, AOC: Affective Organizational Commitment

Table 3 shows the results for discriminant validity acquired through the Fornell-Larcker criterion. As can be gathered from this table, the square root of the AVEs on the diagonals (portrayed in bold) are higher than the correlations between constructs (matching row and column values). This indicates a clearer linkage between the constructs and their individual indicators, as compared to the other constructs in the model. A similar study outcome stated this is indicative of superior discriminant validity. The correlation of the exogenous constructs in our study was observed to be below 0.85 . In view of the above, the discriminant validity for all the constructs in our investigation can be deemed adequately met.

\begin{tabular}{c|cc}
\hline & $A O C$ & $J S$ \\
\hline AOC & $\mathbf{0 . 8 7 6}$ & $\mathbf{0 . 9 2 9}$ \\
JS & 0.338 & \\
\hline
\end{tabular}

Note: Diagonals represent the square root of the average variance extracted while the other entries represent the correlations.

Key: JS: Job Satisfaction, AOC: Affective Organizational Commitment

C.Structural Model Assessment procedure with a resample of 5,000

The structural model can be tested by computing beta $(\beta)$, $\mathrm{R}^{2}$, and the corresponding $\mathrm{t}$-values via a bootstrapping

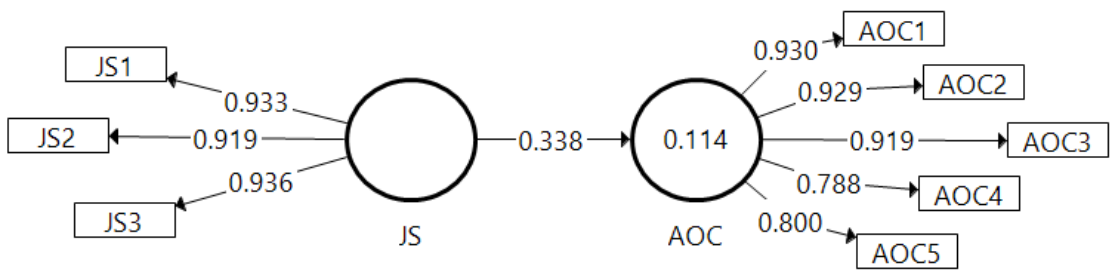

Key: JS: Job Satisfaction, AOC: Affective Organizational Commitment

Fig 2: PLS algorithm results

Eleven percent of the variance in affective organizational

Figure 2 and Table 4 depict the structural model assessment, showing the results of the hypothesis test. Job satisfaction significantly predict affective organizational commitment. Hence, $\mathrm{H} 1$, is accepted with $(\beta=0.338, \mathrm{t}=6.142, \mathrm{p}$ $<0.001)$. commitment is explained by job satisfaction. The values of $R^{2}$ have an acceptable level of explanatory power, indicating a substantial model.

Table 4: Structural assessment results

\begin{tabular}{clllllcc}
\hline \hline Hypothesis & Relationship & Std Beta & Std Error & t-value & p-value & Decision & $\mathrm{R}^{2}$ \\
\hline H3 & JS $\rightarrow$ AOC & 0.338 & 0.055 & 6.142 & 0.000 & Supported & 0.11 \\
\hline \hline
\end{tabular}

Key: JS: Job Satisfaction, AOC: Affective Organizational Commitment

\section{Discussion \& ConClusion}

Based on the proposed model, this study improves the understanding of the role played job satisfaction among employees in government sector in UAE, and highlights relevant implications. The study found that job satisfaction significantly influence affective organizational commitment among employees in government sector in UAE, this is supported by previous studies. It is explained by the fact that the more the employees are satisfied with the job and with the work he/she is doing, the more sense of belonging, attachment, meaning, pride of working in the organization is generated, employees describe their happiness and intention to remain in the organization until retirement, feel unified with the organization to the extent of considering problems faced by the organization as their own.

The results highlighted that job satisfaction is an important predictor of affective organizational commitment. As all the organization's resources have been distributed fairly as well as these resourced must be distributed based on proper and fair procedures - including respect and appreciation - is essential to be achieved, admittedly, their employees are highly likely to develop great job satisfaction.

Given that the employees' affective commitment is greatly 
associated with their satisfaction, the top management in the organization has to measure the employees' perceptions of their needs fulfilment. The managers can evaluate these perceptions by using the current study's questionnaire as per the employees' wish, they were likely to hold more commitment, trust, satisfaction, and control mutuality than when they perceived that they were treated unfairly.

Despite its strengths, this study has a limitation that also suggest areas for future research. This study was limited by police officers of the interior ministry in UAE. In the future research, the researcher suggests to investigate the study hypotheses in other geographical areas, as well as, the sample

\section{APPENDIX}

\section{Appendix A}

Instrument for varibles should include public and private sector to increase the generalization.

The results have been encouraging, as it has managed to throw some lights on affective organizational commitment in the public sector in the UAE. The results revealed that the proposed hypothesis is significant. The independent variable significantly explains $11.4 \%$ of affective organizational commitment. The implications of this study have been deliberated, some directions for future research have been suggested.

\begin{tabular}{cll}
\hline Varible & \multicolumn{4}{c}{ Measure } \\
\hline Job & JS1: All things considered, I am satisfied with my job. \\
Satisfaction & JS2: I like my job. \\
(JS) & JS3: I am generally satisfied with the work I do in this job. \\
& AOC1: I feel a strong sense of belonging to my organization. \\
Affective & AOC2: I feel personally attached to my work organization. \\
Organizational & AOC3: I am proud to tell others I work at my organization. \\
Commitment & AOC4: Working at my organization has a great deal of personal meaning to me. \\
(AOC) & AOC5: I would be happy to work at my organization until I retire. \\
& AOC6: I really feel that the problems faced by my organization are also my \\
& problems.
\end{tabular}

\section{REFERENCES}

1. O. Isaac, Z. Abdullah, T. Ramayah, \& M. Mutahar Ahmed, (2017). Examining the Relationship between Overall Quality, User Satisfaction and Internet Usage: An Integrated Individual, Technological, Organizational and Social Perspective. Asian Journal of Information Technology, 16(1), pp. 100-124.

2. O. Isaac, Z. Abdullah, T. Ramayah, \& A. M. Mutahar, (2017). Internet usage, user satisfaction, task-technology fit, and performance impact among public sector employees in Yemen. The International Journal of Information and Learning Technology, 34(3), pp. 210-241.

3. O. Isaac, Z. Abdullah, T. Ramayah, A. M. Mutahar \& I. Alrajawy, (2017). Towards a Better Understanding of Internet Technology Usage by Yemeni Employees in the Public Sector: An Extension of the Task-Technology Fit (TTF) Model. Research Journal of Applied Sciences, 12(2), pp. 205-223.

4. R. V Krejcie \& D. W. Morgan, (1970). Determining sample size for research activities. Educational and Psychological Measurement, 38 , pp. 607-610.

5. V. R. Kannana \& K. C. Tan, (2005). Just in time, total quality management, and supply chain management: understanding their linkages and impact on business performance. Omega: The International Journal of Management Science, 33(2), pp. 153-162.

6. C. E. Werts, R. L. Linn \& K. G. Jöreskog, (1974). Intraclass reliability estimates: Testing structural assumptions. Educational and Psychological Measurement, 34(1), pp. 25-33.

7. R. B. Kline, (2010). Principles and practice of structural equation modeling (3rd ed.). New York: The Guilford Press. 